\title{
CRITICAL ORGANIZATIONAL SUCCESS FACTORS FOR PUBLIC PRIVATE PARTNERSHIP PROJECTS - A COMPARISON OF SOLICITED AND UNSOLICITED PROPOSALS
}

\author{
Sungmin YUN ${ }^{\mathrm{a}}$, Wooyong JUNG ${ }^{\mathrm{b}}$, Seung Heon HAN ${ }^{\mathrm{c}}$, Heedae PARK ${ }^{\mathrm{d}}$ \\ ${ }^{a}$ Construction Industry Institute, University of Texas at Austin, Austin, Texas, USA \\ ${ }^{b}$ Enterprise Risk Management Team, SK Engineering \& Construction, Seoul, Korea \\ ${ }^{c}$ School of Civil and Environmental Engineering, Yonsei University, Seoul, Korea \\ ${ }^{d}$ Department of Civil, Construction and Environmental Engineering, Iowa State University, Ames, Iowa, USA
}

Received 23 Mar 2012; accepted 20 Jun 2012

\begin{abstract}
Public Private Partnership (PPP) projects are typically initiated through solicited or unsolicited proposals. The difference between the processes according to the proposal mode often leads to different levels of involvement and responsibilities for the public and private sectors. However, no robust research exists to capture the differences, depending on the proposal mode, in the roles and involvement of project participants and the impact of those differences on project success. This study intends to explore the critical organizational success factors contributing to the success of PPP projects according to the proposal mode and to provide practical recommendations for project success from organizational perspectives. To assess the factors, 141 questionnaire surveys were conducted with participants in 32 PPP projects. The major findings indicated that "Project Implementation Capability" had the most critical influence on solicited projects, whereas "Risk Sharing and Mitigation Strategies" was the most significant in unsolicited projects. In addition, "Interorganization Coordination" among project participants was essential to the success for both solicited and unsolicited projects. Government roles and involvement were also critical, although their contributions were relatively less important than other critical organizational success factors. Based on the findings, practical recommendations were provided for the success of solicited and unsolicited projects.
\end{abstract}

Keywords: public private partnership, organizational drivers, solicited proposal, unsolicited proposal, factor analysis, stepwise regression analysis.

\section{Introduction}

Public Private Partnership (PPP) has been promoted as an alternative project delivery system to deliver infrastructure projects such as roads, rails, airports, seaports, waterways, and public buildings in many countries over the past decades (Abdel Aziz 2007). The main concept of PPP schemes is collaboration between the public and private sectors, with different levels of involvement and responsibilities, to provide infrastructure and public services more efficiently (Chan et al. 2010). Numerous PPP projects have been implemented through various arrangements, in accordance with the legal and institutional framework of the host countries (Vives, Benavides 2008). Several procurement methods of PPPs have been used, including the most common method, build-operate-transfer (BOT), and its variations such as build-transfer-operate (BTO), building-own-operate (BOO), build-transfer-lease (BTL), build-lease-transfer (BLT), design-build-finance-operate (DBFO), designbuild-operate-maintain (DBOM), and several others
(Zhang, Kumaraswamy 2001; Abdel Aziz 2007; MOSF 2009).

For the implementation of a PPP project each procurement method has a unique process to develop private initiatives and to select an appropriate private partner to lead a PPP project. In particular, the project development and partner selection process is significantly different depending on whether proposals are solicited or unsolicited. The difference between the processes according to the proposal mode often leads to different levels of involvement and responsibilities of the public and private sectors participating in a PPP project (AECOM Consult 2007). However, the difference in proposal mode and its effects on the level of roles and involvement of project participants in a PPP project have not received adequate attention compared with other PPP research topics. A number of research papers have highlighted other issues, such as government roles and responsibilities (Abdel Aziz 2007; Durchslag et al. 1994; Koch, Buser 2006; Kumaraswamy, Zhang 2001; Pongsiri 2002), concession selection (Ahadzi,

Corresponding author: Seung Heon Han

E-mail:shh6018@yonsei.ac.kr 
Bowles 2001; Zhang 2004, 2005a; Zhang, Kumaraswamy 2001; Zhang et al. 2002), PPP risks (Grimsey, Lewis 2002; Li et al. 2005; Nisar 2007; Thomas et al. 2003; Wang et al. 2000; Xenidis, Angelides 2005), and PPP finance (Devapriya 2006; Levy 1996; Merna, Dubey 1998; Schaufelberger, Wipadapisut 2003; Tiong 1996; Ye, Tiong 2000). In addition, although appropriate management approaches are required to consider the different natures of the PPP projects depending on the proposal modes, no robust evidence exists to recognize the differences in project participants' roles and involvement and to investigate the effects of those differences on the success of the PPP projects.

This study aims to explore multiple organizational factors in the initiation and development of the PPP projects and to determine which factors critically affect project success depending on the proposal mode. To achieve this objective, this study first compared the characteristics of solicited and unsolicited projects based on an extensive literature review. Through the literature review and semi-structured interviews with practitioners, this study also identified the organizational factors that were related to the involvement, and roles and responsibilities of public and private sectors during the initiation and development of PPP projects. A questionnaire survey of project participants in PPP projects was conducted to assess the organizational factors and their relationship with PPP project success. Factor analysis was then conducted to regroup the correlated organizational factors into underlying grouped factors, and stepwise multiple regression analysis was performed to examine the grouped factors contributing to the success of solicited and unsolicited projects. Based on the results, practical recommendations are provided to help project participants effectively initiate and develop a PPP project and prioritize their competencies for the success of a PPP project.

\section{Research background}

\subsection{Characteristics of solicited and unsolicited PPP projects in South Korea}

A PPP project is typically initiated through a solicited or an unsolicited proposal, depending on who develops a proposal and initiates the project. Solicited proposals are developed by the public sector when a project is required to be initiated in accordance with a government's infrastructure development plan, but the solicited proposals require the participation of the private sector because of financial constraints on the government (MOSF 2009). In solicited proposals, the public sector has initially planned and led the implementation of a PPP project. In contrast, unsolicited proposals are initiated by private sector organizations seeking business opportunities. Solicited projects are not formally included in the government's infrastructure development plan but are viable through the PPP scheme. From the literature on the PPP scheme in Korea, we reviewed and summarized the characteristics of solicited and unsolicited PPP projects, as shown in Figure 1. The distinctions between solicited and unsolicited projects are identified in terms of the project development and promoter selection procedure, including the initial proposer, evaluation of project feasibility,

\begin{tabular}{|c|c|c|c|c|c|}
\hline \multicolumn{2}{|r|}{ Solicited Project } & & \multicolumn{3}{|c|}{ Unsolicited Project } \\
\hline \multicolumn{2}{|c|}{$\begin{array}{l}\text { Public Sector } \\
\text { (Government Competent Authority) }\end{array}$} & Initial Proposer & \multicolumn{3}{|c|}{$\begin{array}{l}\text { Private Sector } \\
\text { (Construction Contractors of Financial Investors) }\end{array}$} \\
\hline \multicolumn{2}{|c|}{$\begin{array}{l}\text { - Preliminary Feasibility Study (PFS) } \\
\text { - Value for Money (VfM) Test }\end{array}$} & Project Feasibility & \multicolumn{3}{|c|}{ - Value for Money (VfM) Test } \\
\hline \multicolumn{2}{|c|}{$\begin{array}{l}\text { - Infrastructure facilities which are defined in } \\
\text { the PPP Act } \\
\text { - To meet priority of the investment associated with the } \\
\text { national infrastructure development plan } \\
\text { - To meet requirements of the PPP initiatives such } \\
\text { benefit principle and profit principle }\end{array}$} & Selection Criteria & $\begin{array}{l}\text { - Infras } \\
\text { gover } \\
\text { the P } \\
\text { - To co } \\
\text { feasil } \\
\text { - To ve } \\
\text { the fir } \\
\text { tradit }\end{array}$ & $\begin{array}{l}\text { cture facilities which are not } \\
\text { ent but available to be initiat } \\
\text { scheme } \\
\text { y whether the project satisf } \\
\text { or not } \\
\text { whether the PPP procureme } \\
\text { cial burden of the governme } \\
\text { al procurement }\end{array}$ & $\begin{array}{l}\text { omoted by the } \\
\text { through } \\
\text { conomic } \\
\text { can reduce } \\
\text { rather than }\end{array}$ \\
\hline 1999 & $\begin{array}{l}\text { Whole operation period: } \\
90 \%\end{array}$ & \multirow{3}{*}{$\begin{array}{l}\text { Minimum Revenue } \\
\text { Guarantee }\end{array}$} & 1999 & $\begin{array}{l}\text { Whole operation period: } \\
80 \%\end{array}$ & \\
\hline 2003 & $\begin{array}{lll}15 \text { years after concessionaire start: } \\
1-5 \text { years } & 6-10 \text { years } & 11-15 \text { years } \\
90 \% & 80 \% & 70 \%\end{array}$ & & 2003 & $\begin{array}{l}15 \text { years after concessiona } \\
1-5 \text { years } \quad 6-10 \text { years } \\
80 \%\end{array}$ & $\begin{array}{l}\text { start: } \\
11-15 \text { years } \\
60 \%\end{array}$ \\
\hline 2006 & $\begin{array}{l}10 \text { years after concessionaire start: } \\
1-5 \text { years } \\
75 \% \\
7-10 \text { years } \\
60 \%\end{array}$ & & 2006 & None (Abolished) & \\
\hline \multicolumn{2}{|c|}{ Public Sector > Private Sector } & Operational Risk & \multicolumn{3}{|c|}{ Public Sector < Private Sector } \\
\hline \multicolumn{2}{|c|}{54 Months } & Avg. Preparation Period & \multicolumn{3}{|c|}{36 Months } \\
\hline \multicolumn{2}{|c|}{18 Months } & Avg. Negotiation Period & \multicolumn{3}{|c|}{17 Months } \\
\hline
\end{tabular}

Fig. 1. Comparison of characteristics of solicited and unsolicited projects 
selection criteria and preparation period of a PPP project, and the financial support offered by the government and its influence on risk allocations between public and private sectors.

The procedures for project development and promoter selection are different in solicited and unsolicited projects, depending on the proposal mode, as shown in Figure 2. In a solicited project, a competent authority, which is a governmental agency leading a PPP project, identifies an infrastructure facility in need of construction in accordance with the national infrastructure development plan, conducts the preliminary feasibility study, establishes an implementation plan, and requests proposals from the private sector. The private sector organizes a special purpose company (SPC), develops a proposal, and solicits funds from financial institutions. The Public and Private Investment Management Center in Korea (PIMAC), which is a gatekeeper to public procurement and private infrastructure investment projects in Korea, conducts a preliminary feasibility study, evaluates valuefor-money (VfM), and reviews proposals submitted from the private sector to select a project promoter, who typically formulates a consortium to develop, build, maintain and operate the asset for the concession period of a
PPP project. Following this evaluation, the competent authority selects a negotiation partner from among the proposers; negotiates with the partner to establish the total project cost, concession period, rate of return, user fee, and capital structure; and approves and signs the concession agreement (MOSF 2009). In an unsolicited project, a private sector organization examines a profitable project as a business opportunity, develops a proposal, establishes an implementation plan, and proposes it to a competent authority. The competent authority asks the PIMAC to review the initial proposal. The PIMAC then reviews the proposals and evaluates the VfM of the unsolicited project. Based on the review by the PIMAC, the competent authority approves the proposal and requests proposals from any other private partners to allow bid competition. After receiving proposals from the private sector organizations, including the initial proposer, the competent authority selects a negotiation partner, negotiates the issues of concession agreements, selects a project promoter, and approves and confirms a concession agreement with a private sector organization (MOSF 2009).

These differences in the procedures between solicited and unsolicited projects entail distinctions of organizational factors, such as the level of involvement

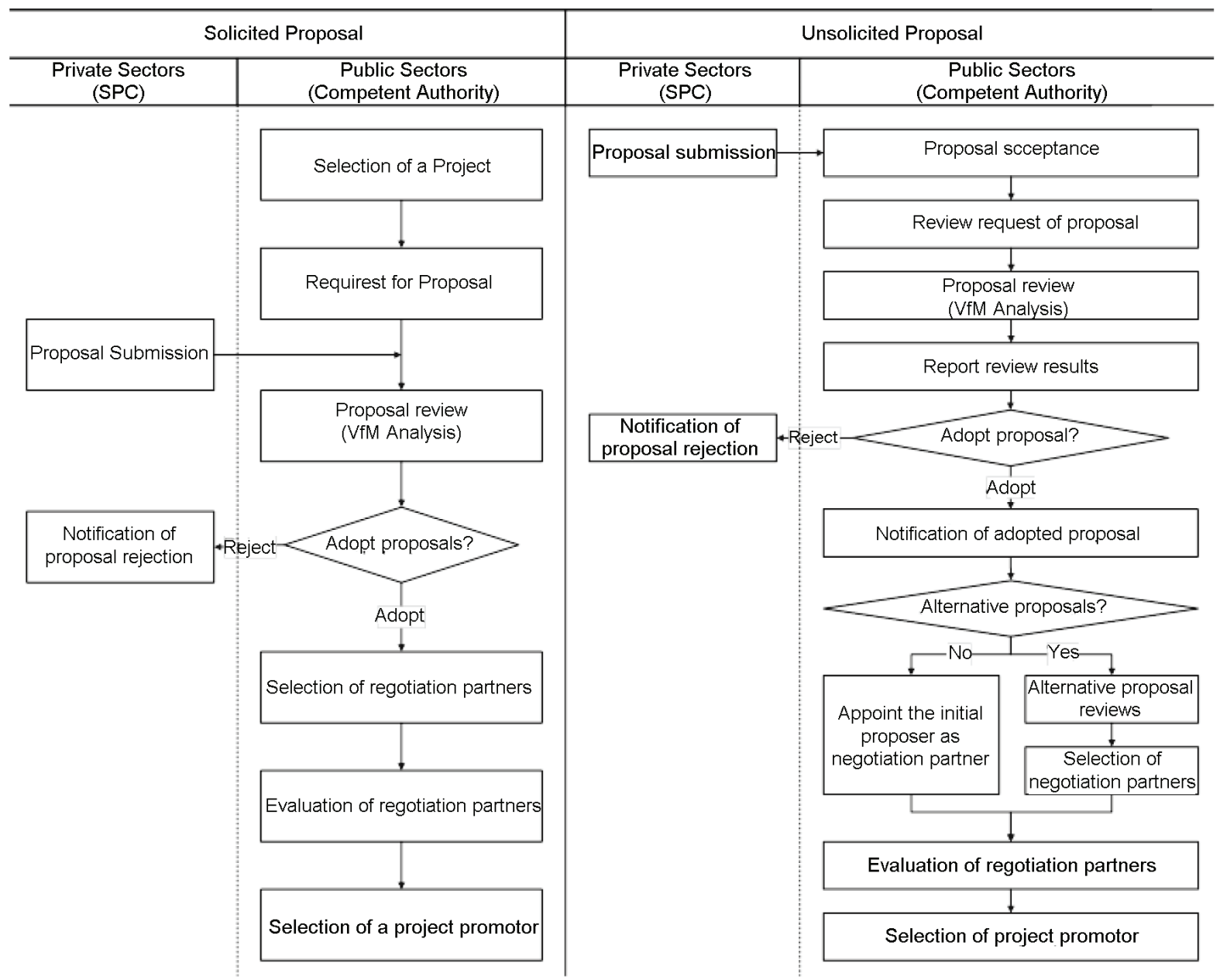

Fig. 2. Project promoter selection procedures depending on the proposal modes (MOSF 2008) 
and support by the government, roles and relationships of project participants, and risk sharing and allocation among public and private sectors. According to recent reports by the Korean Ministry of Strategy and Finance, preparation for a solicited project takes considerably more time than for an unsolicited project (MOSF 2008). On average, for example, highway PPP projects initiated through solicited proposals spent an average of 54 months in the preparation phase prior to commencement of construction, whereas projects initiated through an unsolicited proposal spent an average of 36 months in the preparation phase. By contrast, the average period for negotiation between the public and private sectors in solicited projects (18 months) was similar to that in unsolicited projects (17 months).

The project selection criteria also differed between solicited and unsolicited projects. A candidate for a solicited project can be selected from among the infrastructure facilities that are defined in the PPP Act. The candidate project should be in accordance with the priority of the investment associated with the national infrastructure development plan and meet the requirements of the PPP initiatives (MOSF 2009). In contrast, a candidate for an unsolicited project can be selected from among infrastructure facilities that are not determined by the government but are viable through the PPP scheme. The candidate projects should satisfy economic feasibility, and it needs to be verified whether the PPP procurement can reduce the financial burden of the government more effectively than traditional procurement (MOSF 2009).

In addition, the government provides financial support differently in solicited and unsolicited projects. In particular, the minimum revenue guarantee (MRG) has been considered as one of the most important financial supports offered by the government in many countries, including Korea, and it uses the PPP scheme as an alternative procurement method for infrastructure development. The MRG has played a critical role in reducing exposure to the demand risks of the concessionaire by compensating the concessionaire if operational revenue falls below a specified minimum (Ashuri et al. 2010; Huang, Chou 2006). As shown in Figure 1, before the revision of the PPP scheme in 2005, the government guaranteed minimum operational revenues for a concessionaire for 15 years following the start of the concession in a solicited project, which covers $90 \%$ of the expected operation revenues in the first five years, $80 \%$ in the next five years, and $70 \%$ in the final five years.

Minimum operational revenues were also guaranteed for the concessionaire for 15 years in an unsolicited project, although the rate of the MRG in unsolicited projects is lower than that in solicited projects (i.e. $80 \%$ of the expected operation revenues in the first five years, $70 \%$ in the next five years, and $60 \%$ in the final five years). However, since the change of the legal and institutional framework for the PPP scheme by the amendment of the PPP Act in 2005 (MOSF 2009), these financial supports have been drastically reduced for both solicited and unsolicited projects, primarily because of the increased financial burdens caused by the inaccuracy in demand forecasting in existing PPP projects. The period of the MRG was reduced from 15 years to 10 years for solicited projects, and the rate was also cut to $75 \%$ of expected operational revenue in the first five years and $65 \%$ in the next five years. Furthermore, the MRG for unsolicited projects was entirely eliminated in 2006. Hence, unsolicited projects have become much more exposed to operational risks during the concession period compared with solicited projects.

These distinctions between solicited and unsolicited projects lead to different levels of roles and involvement of the public and private sectors in the initiation and development of a PPP project in terms of the government's roles and supports, the roles and responsibilities of project participants, and risk sharing between the public and private sectors.

\subsection{Critical organizational success factors for PPP projects}

Numerous studies have been conducted to identify what factors critically influence the success of PPP projects since the PPP scheme has been adopted worldwide (Chan et al. 2010; Cheung et al. 2012; Jamali 2004; Jefferies 2006; Li et al. 2005; Ng et al. 2012; Tiong 1996; Zhang 2005b). Most studies have focused primarily on which critical success factors (CSFs) significantly affect PPP project success in general, regardless of differences between solicited and unsolicited proposals. Among the CSFs in previous studies, the roles and involvement of project participants can be divided into the two categories of public and private sectors.

The project stakeholders in the public sector who participate in the development and implementation of a PPP project are competent government authorities, local governments, relevant government-funded corporations and institutes, and non-profit organizations. The project stakeholders play critical roles in the development and implementation of a PPP project, and their roles and involvement can influence project success (El-Gohary et al. 2006). Among them, the government authority, a leading public organization implementing a PPP project, is one of the key players in this process. Therefore, numerous studies have attempted to establish the roles and involvement of the government in the development and implementation of a PPP project. The roles and involvement of the government recognized as CSFs in the previous studies are: contractual guarantee (Tiong 1996); government support (Zhang 2005b); commitment and adequate resourcing of projects by awarding authorities (Dixon et al. 2005); government involvement by provision of guarantees (Chan et al. 2010; Li et al. 2005); and government sponsorship, guarantee and tax reduction (Yuan et al. 2010). The details of the roles and involvement of the government can vary depending on the legal and 
institutional framework of the host countries that have used the PPP schemes.

In the private sector, the project participants for a PPP project are an SPC, construction contractors, financial investors, architects/engineers, construction supervisor/inspector, and similar entities. Among these, the planning and management capabilities of the SPC to implement a PPP project have been widely recognized as CSFs in previous studies. In particular, previous PPP studies have emphasized factors such as a strong and good private consortium (Chan et al. 2010; Tiong 1996), a strong and capable project management team (Dixon et al. 2005; Zhang 2005b), organizational form and managerial strategies (Steijn et al. 2011), leadership of the leading organization (Tiong 1996; Zhang 2005b), and good inter-organizational relationships and coordination (Chan et al. 2010; Li et al. 2005; Zhang 2005b).

In addition, appropriate risk allocation and sharing between public and private sectors has been considered a CSF for implementing a PPP project because a scheme for a PPP project should be determined based on a consensus between public and private sectors (Chan et al. 2010; Li et al. 2005; Zhang 2005b). It was thus important to establish a risk mitigation strategy related to external project stakeholders, such as social support and accordance with public interest (Chan et al. 2010; Li et al. 2005; Zhang 2005b) and permitting and approvals by relevant public organizations (Jefferies 2006).

\section{Research methodology}

\subsection{Research framework}

This research was conducted using an exploratory approach to identify the critical organizational success factors contributing to the performance of both solicited and unsolicited PPP projects. The research framework of this study was developed based on the concept of the previous studies that explored a diversity of critical success factors by combining factor analysis for regrouping correlated variables into underlying factors and regression analysis for identifying critical factors affecting output variables (Chan et al. 2004, 2001). The research process consisted of four steps, as shown in Figure 3. In step 1, the roles and involvement of public and private sectors contributing to project success were identified through an extensive literature review and in-depth interviews with participants in PPP projects. Based on the organizational variables identified in previous studies, 18 organizational variables for successful delivery of PPP projects were identified in the public and private sectors. In step 2, a questionnaire was designed to assess the extent to which organizational variables were satisfied in a PPP project through subjective assessment using Likert scales. The survey was then sent to main project participants, such as SPCs, construction contractors, and financial investors. In step 3, we regrouped the organizational variables that were correlating with each other through factor analysis. Prior to the factor analysis, tests for verifying basic assumptions, including the Kaiser-Meyer-Olkin (KMO) measure of sampling adequacy and Bartlett's test of sphericity, were conducted to determine whether the dataset was appropriate to apply to the factor analysis. Finally, in step 4, a stepwise regression analysis was performed to explore the critical organizational success factors affecting the success of a PPP project in both solicited and unsolicited projects.

\subsection{Data collection}

For this study, the authors collected data using a survey questionnaire that was designed to measure the satisfaction level of 18 organizational variables that were derived from the literature review as input variables and to evaluate one output variable to determine whether the PPP projects were successfully accomplished. The survey was conducted among major private participants in BTO projects that have been implemented in Korea. BTO is one of the PPP arrangements that are typically used in Korea. The BTO type is similar to the BOT type, except that the BTO type transfers the ownership of a facility to the government prior to the operation, in accordance with the institutional framework of Korea (MOSF 2009). Major private participants that have been involved in BTO projects such as SPCs, construction contractors, and financial investors were target respondents for the survey. Operators were not included in the target respondents for the survey because a SPC usually takes the role of a facility operator under the BTO type arrangement, at least in the early concessionaire period. The respondents were asked to rate all organizational variables in terms of satisfaction level according to a seven-point Likert scale $(1=$ very low and $7=$ very high $)$. The success of PPP projects was also measured through seven-point Likert scale $(1=$ very unsuccessful and $7=$ very successful). Total of 141 responses from 32 BTO projects were compiled for the analysis; the overall response rate was approximately $43 \%$. The 141 returned questionnaires consisted of 58 responses from SPCs, 43 responses from construction contractors, and 40 responses from financial investors involved in BTO projects. The respondents had an average of 6.8 years of experience in PPP projects and an average of 17.3 years of experience in their professional fields. The responses were excluded if respondents had less 5 than years of experience in PPP projects and less than 10 years of experience in their own fields. These responses were excluded because the authors assumed a minimum level of experience to achieve sufficient expertise based on a suggestion by the experts who we consulted to verify organizational factors.

As shown in Table 1, there were 18 solicited and 14 unsolicited projects among the 32 projects whose participants were targeted for the questionnaire survey. The average total project cost (TPC) of the solicited projects (US \$ 902.5 million) was greater than that of the unsolicited projects (US \$825.1 million). However, the average percentage of private investment cost to TPC of 


\begin{tabular}{|c|c|c|c|}
\hline STEP I & STEP II & STEP III & STEP IV \\
\hline $\begin{array}{l}\text { Identifying Organizational } \\
\text { Variables }\end{array}$ & $\begin{array}{c}\text { Assessing Organizational } \\
\text { Variables }\end{array}$ & Grouping Underlying Factors & $\begin{array}{c}\text { Exploring Critical Organizational } \\
\text { Factors }\end{array}$ \\
\hline \multirow{2}{*}{\multicolumn{2}{|c|}{$\begin{array}{l}\text { - Leadership of government agency } \\
\text { - Avoidance of duplication with planned facilities } \\
\text { - Support for land acquisition } \\
\text { - Cooperative attitude of government agency } \\
\text { - Minimum revenue guarantees } \\
\text { - Construction subsidies } \\
\text { - Countermeasure of prevention for public complaints } \\
\text { - Expedited permitting and approvals } \\
\text { - Appropriate risk allocation between public and private sector } \\
\text { - Appropriate concessionaire contracts and agreements } \\
\text { - Strategic alignment of project goals and objectives } \\
\text { - Clear project scope definition and documentation } \\
\text { - Clear roles and responsibilities of project participants } \\
\text { - Coordination of SPC with construction contractors } \\
\text { - Coordination of SPC with financial investors } \\
\text { - Coordination of SPC with architects/engineers } \\
\text { - Coordination of SPC with construction supervisors/inspectors } \\
\text { - SPC's organizational structure }\end{array}$}} & Factor B & $\begin{array}{l}\text { Critical Organizational Factors } \\
\text { in Solicited Projects }\end{array}$ \\
\hline & & $\begin{array}{l}\bullet \\
\bullet \\
\bullet\end{array}$ & $\begin{array}{l}\text { Critical Organizational Factors } \\
\text { in Unsolicited Projects }\end{array}$ \\
\hline Literature Review \& Interview & Questionnaire Survey & Exploratory Factor Analysis & Stepwise Regression Analysis \\
\hline
\end{tabular}

Fig. 3. Research framework

Table 1. Descriptive statistics of projects collected through survey

\begin{tabular}{|c|c|c|c|}
\hline Proposal mode & & Solicited projects & Unsolicited projects \\
\hline \multirow[t]{4}{*}{ Number of projects } & Total & 18 & 14 \\
\hline & Road & 10 & 13 \\
\hline & Rail & 3 & 0 \\
\hline & Seaport & 5 & 1 \\
\hline Number of responses & & 75 & 66 \\
\hline Average of total project cost (TPC) & & US \$ 902.5 million & US \$ 825.1 million \\
\hline Average of the percentage of private investment cost of TPC & & $76.1 \%$ & $80.2 \%$ \\
\hline Average of the percentage of government subsidy of TPC & & $23.9 \%$ & $19.8 \%$ \\
\hline
\end{tabular}

the unsolicited projects $(80.2 \%)$ was greater than that of the solicited projects $(76.1 \%)$. As expected, the average of the percentage of government subsidy to TPC for the solicited projects $(23.9 \%)$ was found to be greater than that for unsolicited projects $(19.8 \%)$.

\subsection{Data analysis method}

To explore the critical organizational success factors affecting the success of a PPP project, this study used the combined approach of factor analysis and stepwise regression analysis. Factor analysis is a statistical technique used to identify a relatively small number of individual factors that can be used to represent a relationship among sets of many interrelated variables (Stevens 2009). This technique is powerful in reducing and regrouping individual factors from a larger to a smaller and more critical set based on the scores of responses (Field 2009). The number of individual factors is required, and a set of data is determined by finding the total percentage of variance explained by the examination of individual factors. In this study, principle component analysis (PCA), because of its simplicity and distinctive characteristic of data-reduction capacity, was used to identify the underlying grouped factors. Rotation in factor analysis can make the output more understandable and is usually necessary to facilitate the interpretation of factors. Among various rotation methods, such as Varimax, Quartimax, Equimax, and Promax, this study used extraction with Varimax and Kaiser normalization with the support of SPSS 18.0. Varimax rotation is the most commonly used scheme for orthogonal rotation to clean up the factors, and the method is often used in surveys to examine how groupings of questions measure the same concept (Chan et al. 2004).

Prior to applying factor analysis, this study verified the basic assumption that the dataset was appropriate for applying factor analysis. The KMO measure and 
Bartlett's test of sphericity was used to evaluate the appropriateness of the dataset. A value of KMO between 0 and 1 indicates that the sum of partial correlation is large relative to the sum of correlations, signifying the level of diffusion in the pattern of correlations (Stevens 2009). Therefore, if the statistic is close to 1 , the patterns of correlation are relatively compact, and factor analysis would yield distinct and reliable individual factors (Field 2009). The KMO statistic should be larger than the acceptable threshold of 0.5 at which factor analysis can proceed. In addition, Bartlett's test of sphericity was conducted to reinforce the appropriateness of factor analysis; the test result highlighted the presence of correlation among the variables. The measure is used to test the hypothesis that the correlation matrix is an identity matrix, which indicates that there is no relationship among the items (Stevens 2009). When the value of the test statistic for sphericity is large and the associated significance level is small, the population correlation matrix is not considered an identity matrix (Field 2009).

Following the factor analysis, a stepwise regression analysis was conducted between the success of a PPP project as the dependent variable and 5 underlying grouped factors as independent variables. Stepwise regression analysis is a semi-automated process of building a model by successively adding or removing variables based solely on the t-statistic of their estimated coefficients (Stevens 2009). At each step, the following calculations were typically performed: for each variable currently in the model, the t-statistic for its estimated coefficient is computed, squared, and reported as its "F-to-remove" statistic; for each variable not in the model, the t-statistic that its coefficient would have if it were the next variable added is computed, squared, and reported as its "F-to-enter" statistic. In the next step, the variable is automatically entered with the highest F-to-enter statistic, or the variable with the lowest F-to-remove statistic is removed, in accordance with certain specified control parameters.

\section{Analysis results and discussion}

\subsection{Explanation of underlying grouped factors}

Table 2 shows the KMO measure and Bartlett's test of sphericity to evaluate the appropriateness of the analysis technique. The KMO statistic value is 0.862 , which indicates a good degree of common variance. The value of the test statistic for Bartlett's sphericity is large (chisquared value of 1439.632) at a significance level of 0.001 , implying that the population correlation matrix is not an identity matrix. Because the requirements of the KMO value and the Bartlett's test of sphericity are both met, we concluded that factor analysis was appropriate for this research.

Next, the extraction and rotation of the factors were launched to generate a similar cluster of factors and to obtain a clearer picture of what these factors represent. To determine how many factors would be required to represent each set of data, the total percentage
Table 2. KMO and Bartlett's test for critical organizational factors

\begin{tabular}{lccc}
\hline Kaiser-Meyer- & \multicolumn{3}{c}{ Bartlett's test of sphericity } \\
\cline { 2 - 4 } $\begin{array}{l}\text { Olkin Measure } \\
\text { of Sampling }\end{array}$ & $\begin{array}{c}\text { Approximate } \\
\text { Adequacy }\end{array}$ & $\begin{array}{c}\text { Degree of } \\
\text { freedom }\end{array}$ & Significance \\
\hline 0.862 & 1439.632 & 153 & 0.000 \\
\hline
\end{tabular}

of variance explained by each factor was examined. Principal factor extraction with a Varimax rotation was conducted using SPSS on the 18 organizational variables from the 141 responses. Table 3 presents details and initial statistics for each of the 18 variables. The total variance explained by each variable is listed in the column headed "factor loading". The percentage of the variance and the cumulative percentage of the variance are also shown in Table 3. Five grouped factors were extracted, which accounted for $71.7 \%$ of the variance in responses. The first three factors accounted for $18.3 \%, 16.1 \%$, and $13.9 \%$ of the variance, respectively. Almost all of the factor loadings were greater than 0.5 , and nine were greater than 0.7. In general, the loadings and the interpretation of the factors extracted were found to be reasonably consistent.

One significant finding of the factor analysis was that the grouped factor of the roles and involvement of the government performed better when it was split into two groups: "Government Financial Support" and "Government Leadership and Cooperation". This emphasizes that "Government financial support" was different from "Government Leadership and Cooperation". Another finding was that the roles and involvement of private sectors were regrouped into "Project Implementation Capability" and "Inter-organizational coordination". Finally, the risk sharing between public and private sectors and the mitigation of external project risks (such as public complaints and delays in obtaining permits and approval of relevant public organizations) were merged into one factor of "Risk Sharing and Mitigation Strategy". According to the results of the factor analysis, the five underlying grouped factors were extracted as follows:

\section{- Factor 1: Project Implementation Capability}

This underlying organizational factor consists of four organizational variables that focus primarily on "Project Implementation Capability". This underlying grouped factor includes the appropriate concession contracts and agreements, the strategic alignment of project goals and objectives, a clear project scope definition and document, and clearly defined roles and responsibilities of project participants.

\section{- Factor 2: Inter-organizational Coordination}

Five organizational variables comprise the element of the underlying organizational Factor 2 regarding the "Inter-organizational Coordination" of project participants. This factor is a significant organizational factor and is related to the collaboration of project 
Table 3. Factor structure of organizational factors for the PPP projects

\begin{tabular}{|c|c|c|c|}
\hline Factors & Factor Loading & $\begin{array}{l}\% \text { Variance } \\
\text { Explained }\end{array}$ & $\begin{array}{c}\text { Cumulative \% } \\
\text { Variance Explained }\end{array}$ \\
\hline Factor 1: Project Implementation Capability & & 18.256 & 18.256 \\
\hline Appropriate concessionaire contracts and agreements & 0.799 & & \\
\hline Strategic alignment of project goals and objectives & 0.789 & & \\
\hline Clear project scope definition and documentation & 0.751 & & \\
\hline Clear roles and responsibilities of project participants & 0.739 & & \\
\hline Factor 2: Inter-organizational Coordination & & 16.099 & 34.356 \\
\hline Coordination of SPC with construction contractors & 0.810 & & \\
\hline Coordination of SPC with financial investors & 0.707 & & \\
\hline Coordination of SPC with architects/engineers & 0.679 & & \\
\hline Coordination of SPC with construction supervisors/inspectors & 0.650 & & \\
\hline Project organization structure & 0.512 & & \\
\hline Factor 3: Government Leadership and Cooperation & & 13.954 & 48.310 \\
\hline Leadership of government competent authority & 0.686 & & \\
\hline Avoidance of duplication with similar facilities & 0.678 & & \\
\hline Support for land acquisition & 0.663 & & \\
\hline Cooperative attitude of government competent authority & 0.660 & & \\
\hline Factor 4: Risk Sharing and Mitigation Strategy & & 12.404 & 60.714 \\
\hline Countermeasure of prevention for public complaints & 0.725 & & \\
\hline Expedited permitting and approvals & 0.671 & & \\
\hline Appropriate risk allocation between public and private sector & 0.565 & & \\
\hline Factor 5: Government Financial Support & & 10.996 & 71.711 \\
\hline Minimum revenue guarantees & 0.886 & & \\
\hline Construction subsidies & 0.816 & & \\
\hline
\end{tabular}

participants. The factor includes the coordination of SPCs with construction contractors, financial investors, architects/engineers, construction supervisors/ inspectors, and the project organizational structure.

- Factor 3: Government Leadership and Cooperation This underlying organizational factor has four organizational variables pertaining to the elaboration of "Government Leadership and Cooperation". This factor consists of the leadership of the government agency, the avoidance of duplication with similar facilities, the support for land acquisition, and the cooperative attitude of the government agency.

- Factor 4: Risk Sharing and Mitigation Strategy Three organizational variables comprise the element of the underlying organizational Factor 4 regarding "Risk Sharing and Mitigation Strategy" among the project participants. This factor includes the countermeasure of avoidance of public complaints, expedited permitting and approvals, and appropriate risk allocation between public and private sectors.

- Factor 5: Government Financial Support

There are two items in this factor that are related to the extent of "Government Financial Support". The MRG and construction subsidies are included in this factor.

\subsection{Stepwise multiple regression results}

Two stepwise multiple regression analyses were conducted between the success of a PPP project as the dependent variable and the five underlying grouped organizational factors as the independent variables using SPSS 18.0 in terms of solicited and unsolicited projects. Five factor scores for each respondent were calculated using a regression method in SPSS. These factor scores formed the dataset for the stepwise regression multiple regression analysis. An entrance criterion was set that an F-statistic must be significant at the level of 0.05 . Table 4 shows the standardized regression coefficient $(\beta)$, coefficient of determination $\left(R^{2}\right)$, adjusted $\mathrm{R}$-square value (Adjusted $\left.R^{2}\right)$, change in R-square $\left(\Delta R^{2}\right)$, and significance level (p-value). The sample sizes adopted for the analysis were 75 responses for the solicited projects and 66 responses for the unsolicited projects after refining the dataset on the basic assumptions of outliers and normality for regression.

In the stepwise multiple regression for the solicited projects, the independent variables whose F-statistics were less than or equal to the entrance criteria $(p \leq 0.05)$ were, in descending order of significance, "Project Implementation Capability” (Factor 1), "Inter-organizational 
Coordination" (Factor 2), "Risk Sharing and Mitigation Strategy" (Factor 4), "Government Financial Support" (Factor 5), and Government Leadership and Cooperation" (Factor 3). The $R$-square value was 0.487 , and the adjusted $R$-square was 0.449 . In sum, these values indicated that $48.7 \%$ of the personal perception of the PPP project success variance was explained by the five grouped factors. All of the factors - "Project Implementation Capability" (0.461), "Inter-organizational Coordination" (0.336), "Risk Sharing and Mitigation Strategy" (0.284), "Government Financial Support" (0.204), and "Government Leadership and Cooperation" (0.199) - are statistically significant at the 0.05 significance level and contributed considerably to the prediction of the level of the success of a PPP project.

Regarding the stepwise multiple regression for the unsolicited projects, "Risk Sharing and Mitigation Strategy" (Factor 4), "Inter-organizational Coordination" (Factor 2), "Project Implementation Capability" (Factor 1), and "Government Financial Support" (Factor 5) were found to be significantly different at $p \leq 0.05$. Overall, $58.2 \%$ of the personal perception of the PPP project success variance was explained by these four group factors. The $R$-square value was 0.582 , and the adjusted $R$-square was 0.555 . Four factors - "Risk Sharing and Mitigation Strategy" (0.549), "Inter-organizational Coordination" (0.407), "Project Implementation Capability" (0.263), "Government Financial Support" (0.168) - were statistically significant at the 0.05 significance level and contributed considerably to the prediction of the success of a PPP project.

The $R$-squares of the stepwise multiple regressions for solicited and unsolicited projects were 0.487 and 0.582 , respectively. The $R$-squares were slightly low because this study used the underlying grouped factors extracted in factor analysis to eliminate the effects of multicollinearity in the multiple regression analysis. Generally, the multicollinearity appears in a multiple regression analysis in which two or more independent variables are highly correlated with each other and affects the inflation of $R$-square. Usually, the $R$-square indicates the goodness of fitness of a regression model and is used as a statistical measure of how well the regression line approximates the real data points (Stevens 2009). Although the exploratory powers of the regression models are not significantly high, it seems worthwhile to explore the critical organizational success factors affecting the success of a PPP project.

\subsection{Discussion of regression results}

The stepwise multiple regression results show that the critical organizational success factors affecting the success of a PPP project are different depending on the proposal mode of the project. As discussed in relation to the characteristics of solicited and unsolicited PPP projects, the distinction of the project initiation, development process, and roles and involvement of project participants of both PPP schemes could cause the difference in the critical organizational factors contributing to the success of a PPP project. This difference can be made visible with the results of the stepwise regression. The order and relative importance of the critical organizational success factors were differently elicited between solicited and unsolicited projects in the stepwise regression results, as shown in Table 4.

As indicated in the regression findings, "Project Implementation Capability" was the most important underlying grouped factor contributing to the success of a PPP project in the solicited projects, whereas it was the third most critical factor in the unsolicited projects. Solicited projects are typically proposed by the government for constructing an infrastructure facility that needs to be

Table 4. Stepwise multiple regression results in solicited and unsolicited projects

\begin{tabular}{|c|c|c|c|c|c|}
\hline Independent variables (underlying factors) & $\begin{array}{l}\text { Standardized } \\
\text { coefficient }(\beta)\end{array}$ & $R^{2}$ & $\begin{array}{c}\text { Adjusted } \\
R^{2}\end{array}$ & $\Delta R^{2}$ & $p$-value \\
\hline \multicolumn{6}{|l|}{ Solicited Projects } \\
\hline Factor 1: Project Implementation Capability & 0.461 & 0.221 & 0.210 & 0.221 & 0.000 \\
\hline Factor 2: Inter-organizational Coordination & 0.336 & 0.325 & 0.306 & 0.104 & 0.000 \\
\hline Factor 4: Risk Sharing and Mitigation Strategy & 0.284 & 0.410 & 0.385 & 0.085 & 0.002 \\
\hline Factor 5: Government Financial Support & 0.204 & 0.448 & 0.417 & 0.038 & 0.022 \\
\hline Factor 3: Government Leadership and Cooperation & 0.199 & 0.487 & 0.449 & 0.039 & 0.026 \\
\hline \multicolumn{6}{|l|}{ Size of sample adopted $=75$} \\
\hline \multicolumn{6}{|l|}{ Unsolicited Projects } \\
\hline Factor 4: Risk Sharing and Mitigation Strategy & 0.549 & 0.307 & 0.296 & 0.307 & 0.000 \\
\hline Factor 2: Inter-organizational Coordination & 0.407 & 0.492 & 0.475 & 0.185 & 0.000 \\
\hline Factor 1: Project Implementation Capability & 0.263 & 0.554 & 0.533 & 0.062 & 0.002 \\
\hline Factor 5: Government Financial Support & 0.168 & 0.582 & 0.555 & 0.028 & 0.047 \\
\hline Size of sample adopted $=66$ & & & & & \\
\hline
\end{tabular}


built for which the government does not have sufficient funds. It is thus typical that solicited projects are initiated after completion of the initial construction planning and verification of operational profitability by the government. Thus, private participants need to further elaborate the concessionaire contracts and agreements between the public and private sectors and align the project goals and objectives for a solicited PPP project more than for an unsolicited project. Moreover, prior to the commencement of construction, the project scope of the solicited projects and the roles and responsibilities of the project participants also need to be defined and established more clearly with a solicited project than with an unsolicited project.

As shown in Table 4, "Inter-organizational Coordination" was the second most critical organizational success factor for both the solicited and the unsolicited projects. A PPP project has a distinctive project organizational structure that establishes the SPC-oriented organizational relationships among the project participants. The inter-organizational relationships are typically concentrated in an SPC, which is the temporary project company that is established based on the funds from various financial sources. The SPC signs the concessionaire agreement with the government and has the authority to enter into contracts for implementing the PPP project with the project participants. Among the project participants, the SPC needs to have good relationships and coordinate the interests of the key financial investors, such as construction contractors and financial investors who substantially invest funds in the establishment of the SPC. In addition, the relationship with architects and engineers needs to be considered for securing the high quality of engineering deliverables. Finally, the SPC should have good relationships with construction supervisors and inspectors to guarantee the quality of the construction.

The organizational factor of "Risk Sharing and Mitigation Strategy" is the most important in the unsolicited projects, whereas it is the third most important in the solicited projects. For implementation of both solicited and unsolicited projects, it is crucial to properly allocate various risks that may occur during the execution of a PPP project between the public and private sectors at the inception of the project. Specifically, the unsolicited projects have more possibilities of being exposed to the latent risks in organizational and financial aspects, although the risk sharing between the public and private sectors might be quite well established. Therefore, unsolicited projects require maintaining more continuous and dedicated efforts on the part of the private participants for project success compared with solicited projects. In addition, the risk mitigation strategy for mitigating external organizational risks, such as delays in obtaining permits and approvals and concerns about public resistance, should be considered. When these risks are not properly managed, major schedule delays often occur during construction; hence, the "Risk Sharing and Mitigation Strategy" needs to be considered in the early stages of a PPP project.
As shown in Table 4, "Government Financial Support" was observed to be the fourth most critical organizational success factor for the success of both the solicited and the unsolicited PPP projects. Numerous studies recognized and emphasized the roles and involvement of the government; in particular, financial supports such as construction subsidies and minimum revenue guarantees by the government have played significant roles in the success of PPP projects. Because the government provides a certain portion of the construction costs for a PPP project in construction subsidies, the private sector organizations can reduce the financial burdens including costs related to financing and interest. In addition, the minimum revenue guarantee enables the private sector organizations to secure the revenues and profits during the concessionaire period.

As indicated in the regression results, "Government Leadership and Cooperation" was the fifth most critical factor contributing to the success of the solicited projects. This signifies that the government cooperates effectively with the private sector, which requires leadership and a cooperative attitude from the government competent authority, support for land acquisition, and avoidance of duplication with similar facilities in the neighboring area after the start of the concession. However, this factor was not statistically significant in the success of the unsolicited projects. This difference is primarily because unsolicited projects are usually promoted by the private sector; therefore, "Government Leadership and Cooperation" probably have an insignificant influence on the success of unsolicited projects.

\section{Practical recommendations for PPP projects from the organizational perspective}

As shown in the results of the factor analysis and the stepwise regression, the critical organizational success factors contributing to the PPP project success were different between solicited and unsolicited projects. The results indicated that the majority of the critical organizational success factors were associated with the organizational project competencies of the private sector, including planning, contracting, inter-organizational coordination, and risk sharing and mitigation strategy in both the solicited and the unsolicited projects. From this standpoint, the findings of this research can provide practical recommendations for how project participants should concentrate their organizational competencies for PPP project success depending on the type of proposal mode.

The overall recommendations to the PPP practitioners are provided in terms of establishing good project governance and fostering inter-organizational coordination and collaboration for both solicited and unsolicited projects. First, as stated well in UN-ESCAP (2004), the PPP project organization structure and relationships among project participants should be developed based on good project governance, which is a critical element 
of a PPP project. The good project governance is fairly associated with the accountabilities and responsibilities to align project goals and objectives. Project governance can also be applied to evaluate the performance of a PPP project in terms of the decision-making framework and process (Abednego, Ogunlana 2006). In this respect, Abdel Aziz (2007) and Baizakov (2008) suggested the main principles for developing good project governance, including the right decision at the right time, contract fairness, information transparency, responsiveness, continuous project control and monitoring, equality, effectiveness and efficiency, and accountability. These principles of good project governance are also found in our research and can help improve project performance and contribute to proper risk allocation between the public and private sectors.

Second, project participants should foster interorganizational coordination and collaboration with each other. PPP projects are typically exposed to the potential risk of inter-organizational conflicts among the participating organizations because the project participants have different interests (Levitt et al. 2009). For example, the government intends to provide public services efficiently while minimizing the financial burden through the PPP scheme. The SPC, conversely, aims to gain an operational profit margin, the construction contractor has an interest in the construction profit margin, and the financial investor pursues long-term interest income during the concession period against a financial investment. Hence, proper coordination and collaboration among project participants is critical to success, regardless of the PPP proposal mode.

Third, the specific recommendation for the success of solicited projects is to enhance project organization competencies. The project organization should enhance the project organizational competencies of participants that are critical to achieving project team alignment, effective execution, and the proper allocation of organizational resources during the initiation and development of a PPP project. As is well supported by the results of regression analysis, the enhancement of project organizational competencies can lead to the improvement of project implementation capability that are the fundamental elements for the initiation and development of a PPP project.

Finally, the specific recommendation for unsolicited projects is to develop alternative risk mitigation strategies to reduce operational risks during the concession period. In private sector aspects, the MRG is the most important government support to decide "go" or "no-go" of a given PPP project. However, the legal and institutional framework has changed to reduce or eliminate the support of the MRG in both solicited and unsolicited projects worldwide. Specifically, unsolicited projects have a tendency to gain less support from the government because these projects are primarily initiated by the private sector and thus tend to have less legitimacy to be backed by the government than do solicited projects. Although the financial support provided by the government is crucial for the success of a PPP project, the private sector needs to develop alternative strategies to alleviate the operational risks in its upcoming PPP projects.

The major findings and recommendations were also validated though expert interviews with 10 major stakeholders, including government agencies, SPCs, construction contractors, and financial investors. These experts mostly agreed that comprehensive government roles and involvement, including leadership and cooperation and the financial support of the government, were critical to project success, particularly for solicited projects. In addition, they emphasized that inter-organizational coordination should be improved for both solicited and unsolicited PPP projects, which requires an inter-organizational role of the project participants. Several practical strategies for effective PPP implementation were also addressed by the experts. First, government authority needs to complement the legal and institutional framework for accelerating the roles and involvement of the government. In addition, alternative financial supports, in place of the MRG, should be devised for both solicited and unsolicited projects because of the rapid changes in government policy such as the case of Korea's elimination of MRG support. Other experts suggested the inclusion of profitable supplementary facilities during the main part of a project to improve the soundness of the PPP conditions. For example, the addition of a shopping mall to the main part of an infrastructure project can increase the overall rate of return while minimizing the risks of the project. In line with the supports by the government to improve the project conditions, the government sector also strongly stressed that the private sector needs to improve the coordination capabilities of SPCs as well as key construction contractors for managing a wide range of project participants.

\section{Conclusions}

Although numerous studies have been conducted to identify CSFs for PPPs, each study identified CSFs for PPPs only from a general perspective, regardless of the unique characteristics of PPPs with respect to different proposal modes. To deepen the understanding of CSFs for PPPs, this study investigated critical organizational factors for the success of solicited and unsolicited projects. The results of the factor analysis and stepwise multiple regression provided practical recommendations for the success of solicited and unsolicited projects. For both solicited and unsolicited projects, the key project participants should establish good project governance to align the project goals and objectives with the various interests of project participants and foster inter-organizational coordination and collaboration to alleviate the potential risk of inter-organizational conflicts among project participants. For the solicited projects, the enhancement of project organizational competencies was considered more 
important to improve the project implementation capability. For the unsolicited projects, the development of alternative risk mitigation strategies was a crucial influence to reduce the operational risk during the concession period, considering changes in the legal and institutional framework of the PPP scheme such as the elimination of MRG policy in Korea.

Countries that have used PPPs have different economic, legal, and institutional environments; therefore, this study could be expected to be a foundation for studies on CSFs for different PPPs. In this respect, the results of this study provide strategic breakthroughs for public sector organizations to improve institutional and legal frameworks to facilitate PPP projects in countries in which PPP procurement systems have matured to some extent. In addition, these findings can provide insight into the optimal managerial focus during project inception for the major private sectors - in particular, SPCs, construction contractors, and financial investors. Despite these contributions, the study is limited in scope because it focused on CSFs from the organizational perspective. Future procedural research will concentrate on identifying CSFs and their impacts in association with different project modalities, such as BTO and BTL projects. Exploring the impacts of various CSFs on the overall perspectives of project success will be another interesting topic for further research.

\section{Acknowledgement}

This research was supported by the Basic Science Research Program through the National Research Foundation of Korea (NRF), a grant funded by the Ministry of Education, Science and Technology (2012-0000178).

\section{References}

Abdel Aziz, A. M. 2007. Successful delivery of public-private partnerships for infrastructure development: Journal of Construction Engineering and Management 133(12): 918-931.

http://dx.doi.org/10.1061/(ASCE)0733-9364(2007)133:12(918)

Abednego, M. P.; Ogunlana, S. O. 2006. Good project governance for proper risk allocation in public-private partnerships in Indonesia, International Journal of Project Management 24(7): 622-634. http://dx.doi.org/10.1016/j.ijproman.2006.07.010

AECOM Consult. 2007. User guidebook on implementing public-private partnerships for transportation infrastructure projects in the United States. Arlington, Virginia: Federal Highway Administration.

Ahadzi, M.; Bowles, G. 2001. The private finance initiative: the procurement process in perspective, in $17^{\text {th }}$ Annual ARCOM Conference, 5-7 September 2001, University of Salford, Association of Researchers in Construction Management. Vol. 1, 991-999.

Ashuri, B.; Kashani, H.; Molenaar, K.; Lee, S. 2010. A valuation model for choosing the optimal minimum revenue guarantee (MRG) in a highway project: a real option approach, in ASCE Proceedings of the 2010 Construction Research Congress, 8-10 May 2010, Banff, Alberta, Canada.
Baizakov, S. 2008. Guidebook on promoting good governance in public-private partnership. United Nations Economic Commission for Europe, Geneva, Switzerland.

Chan, A. P. C.; Chan, D. W. M.; Chiang, Y.; Tang, B.; Chan, E. H. W.; Ho, K. S. K. 2004. Exploring critical success factors for partnering in construction projects, Journal of Construction Engineering and Management 130(2): 188-198.

http://dx.doi.org/10.1061/(ASCE)0733-9364(2004)130:2(188)

Chan, A. P. C.; Ho, D. C. K.; Tam, C. 2001. Design and build project success factors: multivariate analysis, Journal of Construction Engineering and Management 127(2): 93-100.

http://dx.doi.org/10.1061/(ASCE)0733-9364(2001)127:2(93)

Chan, A. P. C.; Lam, P. T. I.; Chan, D. W. M.; Cheung, E.; Ke, Y. 2010. Critical success factors for PPPs in infrastructure developments: Chinese perspective, Journal of Construction Engineering and Management 136(5): 484-494. http://dx.doi.org/10.1061/(ASCE)CO.1943-7862.0000152

Cheung, E.; Chan, A. P. C.; Kajewski, S. 2012. Factors contributing successful public private partnership projects: comparing Hong Kong with Australia and the United Kingdom, Journal of Facility Management 10(1): 45-58. http://dx.doi.org/10.1108/14725961211200397

Devapriya, K. 2006. Governance issues in financing of publicprivate partnership organisations in network infrastructure industries, International Journal of Project Management 24(7): 557-565.

http://dx.doi.org/10.1016/j.ijproman.2006.07.003

Dixon, T.; Pottinger, G.; Jordan, A. 2005. Lessons from the private finance initiative in the UK: benefits, problems and critical success factors, Journal of Property Investment \& Finance 23(5): 412-423. http://dx.doi.org/10.1108/14635780510616016

Durchslag, S.; Puri, T.; Rao, A. 1994. The promise of infrastructure privatization, McKinsey Quarterly 1:3-3.

El-Gohary, N. M.; Osman, H.; El-Diraby, T. E. 2006. Stakeholder management for public private partnerships, International Journal of Project Management 24(7): 595-604. http://dx.doi.org/10.1016/j.ijproman.2006.07.009

Field, A. P. 2009. Discovering statistics using SPSS:(and sex and drugs and rock'n'roll). SAGE publications Ltd.

Grimsey, D.; Lewis, M. K. 2002. Evaluating the risks of public private partnerships for infrastructure projects, International Journal of Project Management 20(2): 107-118. http://dx.doi.org/10.1016/S0263-7863(00)00040-5

Huang, Y. L.; Chou, S. P. 2006. Valuation of the minimum revenue guarantee and the option to abandon in BOT infrastructure projects, Construction Management and Economics 24(4): 379-389. http://dx.doi.org/10.1080/01446190500434997

Jamali, D. 2004. Success and failure mechanisms of public private partnerships (PPPs) in developing countries: insights from the Lebanese context, International Journal of Public Sector Management 17(5): 414-430. http://dx.doi.org/10.1108/09513550410546598

Jefferies, M. 2006. Critical success factors of public private sector partnerships: a case study of the Sydney Super Dome, Engineering, Construction and Architectural Management 13(5): 451-462. http://dx.doi.org/10.1108/09699980610690738

Koch, C.; Buser, M. 2006. Emerging metagovernance as an institutional framework for public private partnership networks in Denmark, International Journal of Project Management 24(7): 548-556.

http://dx.doi.org/10.1016/j.ijproman.2006.07.001

Kumaraswamy, M.; Zhang, X. 2001. Governmental role in BOT-led infrastructure development, International Journal of Project Management 19(4): 195-205. http://dx.doi.org/10.1016/S0263-7863(99)00069-1 
Levitt, R. E.; Henisz, W. J.; Ssttel, D. 2009. Defining and mitigating the governance challenges of infrastructure project development and delivery, in 2009 Conference on Leadership and Management of Construction, 2009, Fallen Leaf Lake, Lake Tahoe, California, 5-8.

Levy, S. M. 1996. Build, operate, transfer: paving the way for tomorrow's infrastructure. New York: Wiley. $411 \mathrm{p}$.

Li, B.; Akintoye, A.; Edwards, P.; Hardcastle, C. 2005. Critical success factors for PPP/PFI projects in the UK construction industry, Construction Management \& Economics 23(5): 459-471. http://dx.doi.org/10.1080/01446190500041537

Merna, T.; Dubey, R. 1998. Financial engineering in the procurement of projects. Asia Law \& Practice. $150 \mathrm{p}$.

MOSF. 2008. Public Hearings Resources for 2008 2012 National Financial Management Plan - Private Investment Division. Ministry of Strategy and Finance, Gwacheon, Korea.

MOSF. 2009. Basic Plan for Private Participation in Infrastructure. Ministry of Strategy and Finance, Gwacheon, Korea.

Ng, S. T.; Wong, Y. M. W.; Wong, J. M. W. 2012. Factors influencing the success of PPP at feasibility stage - a tripartite comparison study in Hong Kong, Habitat International 36(4): 423-432.

http://dx.doi.org/10.1016/j.habitatint.2012.02.002

Nisar, T. M. 2007. Risk management in public-private partnership contracts, Public Organization Review 7(1): 1-19. http://dx.doi.org/10.1007/s11115-006-0020-1

Pongsiri, N. 2002. Regulation and public-private partnerships, International Journal of Public Sector Management 15(6): 487-495. http://dx.doi.org/10.1108/09513550210439634

Schaufelberger, J. E.; Wipadapisut, I. 2003. Alternate financing strategies for build-operate-transfer projects, Journal of Construction Engineering and Management 129(2): 205-213.

http://dx.doi.org/10.1061/(ASCE)0733-9364(2003)129:2(205)

Steijn, B.; Klijn, E-H; Edelenbos, J. 2011. Public-private partnership: added value by organizational from or management?, Public Administration 89(4): 1235-1252. http://dx.doi.org/10.1111/j.1467-9299.2010.01877.x

Stevens, J. 2009. Applied multivariate statistics for the social sciences. $5^{\text {th }}$ ed. Lawrence Erlbaum. 720 p.

Thomas, A.; Kalidindi, S. N.; Ananthanarayanan, K. 2003. Risk perception analysis of BOT road project participants in India, Construction Management and Economics 21(4): 393-407. http://dx.doi.org/10.1080/0144619032000064127

Tiong, R. L. K. 1996. CSFs in competitive tendering and negotiation model for BOT projects, Journal of Construction
Engineering and Management 122(3): 205-211.

http://dx.doi.org/10.1061/(ASCE)0733-9364(1996)122:3(205)

UN-ESCAP. 2004. Human settlements: what is good governance? [online], [cited 28 Octorber 2010]. Available from Internet: http://www.unescap.org/pdd/prs/projectactivities/ongoing/gg/governance.asp

Vives, A.; Benavides, J. 2009. Public procurement methods to enhance private investments in infrastructure, in 2009 Conference on Leadership and Management of Construction, 2009, Fallen Leaf Lake, Lake Tahoe, California.

Wang, S. Q.; Tiong, R. L. K.; Ting, S.; Ashley, D. 2000. Evaluation and management of political risks in China's BOT projects, Journal of Construction Engineering and Management 126(3): 242-250.

http://dx.doi.org/10.1061/(ASCE)0733-9364(2000)126:3(242)

Xenidis, Y.; Angelides, D. 2005. The financial risks in buildoperate-transfer projects, Construction Management and Economics 23(4): 431-441.

http://dx.doi.org/10.1080/01446190500041552

Ye, S.; Tiong, R. 2000. Government support and risk-return trade-off in China's BOT power projects, Engineering, Construction and Architectural Management 7(4): 412-422. http://dx.doi.org/10.1108/eb021163

Yuan, J.-F.; Skibniewski, M. J.; Li, Q.; Shan, J. 2010. The driving factors of China's public-private partnership projects in metropolitan transportation system: public sector's view point, Journal of Civil Engineering and Management 16(1): 5-18. http://dx.doi.org/10.3846/jcem.2010.01

Zhang, X. 2004. Concessionaire selection: methods and criteria, Journal of Construction Engineering and Management 130(2): 235-244.

http://dx.doi.org/10.1061/(ASCE)0733-9364(2004)130:2(235)

Zhang, X. 2005a. Criteria for selecting the private-sector partner in public-private partnerships, Journal of Construction Engineering and Management 131(6): 631-644.

http://dx.doi.org/10.1061/(ASCE)0733-9364(2005)131:6(631)

Zhang, X. 2005b. Critical success factors for publicprivate partnerships in infrastructure development, Journal of Construction Engineering and Management 131(1): 3-14.

http://dx.doi.org/10.1061/(ASCE)0733-9364(2005)131:1(3)

Zhang, X.; Kumaraswamy, M. M. 2001. Hong Kong experience in managing BOT projects, Journal of Construction Engineering and Management 127(2): 154-162.

http://dx.doi.org/10.1061/(ASCE)0733-9364(2001)127:2(154)

Zhang, X.; Zheng, W.; Palaneeswaran, E. 2002. Concessionaire selection for build-operate-transfer tunnel projects in Hong Kong, Journal of Construction Engineering and Management 128(2): 155-163.

http://dx.doi.org/10.1061/(ASCE)0733-9364(2002)128:2(155)

Sungmin YUN. PhD, Postdoctoral Fellow in the Construction Industry Institute at the University of Texas at Austin, USA. Research interests include public private partnership, corporate and project performance assessment and benchmarking, big data analytics, project financing, strategic business-project alignment, organizational issues, interface management, and project risk management.

Wooyong JUNG. PhD, Structural P.E., Team Leader in the Enterprise Risk Management at SK Engineering and Construction, Co. Ltd., Seoul, Korea. Research interests include risk management, project financing, totals solution provider, system management, cost control, engineering management, organization management.

Seung Heon HAN. PhD, Professor in the School of Civil and Environmental Engineering, Yonsei University, Korea. He holds an M.S in Urban Planning and a PhD in Civil Engineering. Research interests include construction policy development, development of risk analysis model, project management, emerging construction technologies, and construction management process standardization.

Heedae PARK. PhD, Postdoctoral research associate in the Department of Civil, Construction and Environmental Engineering, Iowa State University, USA. Formerly graduate student of Yonsei University, Korea. Research interests: big data analytics, organizational issues, network analysis, international construction, and risk management. 